(2) Open Access Full Text Article

\title{
Investigation of pulmonary infection pathogens in neurological intensive care unit
}

\author{
This article was published in the following Dove Press journal: \\ Therapeutics and Clinical Risk Management \\ 20 January $201 \mathrm{I}$ \\ Number of times this article has been viewed
}

\section{Fengying Quan \\ Guangwei Liu \\ Liang Wang \\ Xuefeng Wang}

Department of Neurology, The First Affiliated Hospital of Chongqing Medical University, Chongqing, China
Correspondence: Guangwei Liu Department of Neurology, The First Affiliated Hospital of Chongqing Medical University, I You Yi Road, Chongqing 4000I6, China

Tel +862389012878

Fax +862368708697

Email cyliuguangwei@।26.com
Purpose: The purpose of this study is to investigate the distribution and antimicrobial susceptibility of pathogenic bacteria in inpatients with pulmonary infection in the neurological intensive care unit (NICU).

Methods: A total of 947 sputum specimens of 428 inpatients from May 2007 to May 2008 in the NICU were enrolled in the study, and bacterial identification and antibiotic susceptibility tests were analyzed using a VITEK 2 system.

Results: A total of 400 positive bacterial strains were separated from 947 sputum specimens, with Gram-negative bacteria accounting for $69.0 \%$ of the total strains collected. The most common strain of Gram-negative bacteria was Klebsiella pneumoniae (20.5\%). Gram-positive bacteria accounted for $10.0 \%$ of the total strains, with the most common strain being Staphylococcus aureus (2.5\%). Fungal species accounted for $21.0 \%$ of the total strains, and the most common strain collected was Candida albicans (12.25\%). Imipenem was the most effective antibiotic against Gram-positive and Gram-negative bacteria. The drug resistance rate of Gram-positive bacteria to penicillin $\mathrm{G}$ was $100 \%$, and the Gram-positive bacteria were $100 \%$ sensitive to teicoplanin, vancomycin, and linezolid.

Conclusions: Gram-negative bacterial infections account for the majority of pulmonary infections in the NICU, with fungal infections being the second most common infection type observed. In addition, fungal infections seem to be related to mortality in the NICU.

Keywords: nosocomial infection, pulmonary infection, drug resistance, neurological intensive care unit

\section{Introduction}

The neurological intensive care unit (NICU) is the main place where neurocritical patients are admitted. The chance of infection in the NICU is higher than in the general wards because operations such as endotracheal intubation, incision, sputum suction, and catheterization are performed. Pulmonary infection is a major form of nosocomial infection, and it is associated with increased length of stay and mortality in intensive care units (ICUs). ${ }^{1,2}$ With the new types of antibiotics widely used in the clinic, the emergence of pathogenic bacteria have increased, and multidrug resistant and high drug-resistant strains are having a negative impact on the prognosis of inpatients. ${ }^{3}$ To understand the distribution and changes in trends of pathogenic bacteria in NICU, we carried out bacterial culture and antimicrobial susceptibility tests on sputum specimens of inpatients from May 2007 to May 2008 in the NICU of our hospital. 


\section{Methods}

This research was approved as a clinical prospective observational cohort study by the ethics committee of the First Affiliated Hospital of Chongqing Medical University in Chongqing, China. Informed consents were obtained from all subjects prior to the study. Our NICU comprises 18 beds with an average of $1500 \mathrm{admissions/year.}$

A total of 947 sputum specimens were collected from 428 patients with pulmonary infection after admission in our NICU from May 1, 2007 to May 31, 2008. All patients were admitted to the NICU for more than $48 \mathrm{~h}$. The standardized criteria for respiratory infections include fever, cough, increased leukocyte count $\left(>10 \times 10^{9} / \mathrm{L}\right)$, increased neutrophil percentages $(>80 \%)$, and harsh breath sounds with dry and medium rales or wheezy phlegm. Signs of pulmonary infection were observed by chest X-ray. Routine sputum specimens were submitted for tests, and bronchoalveolar lavage fluid was collected if the patient underwent tracheal intubation or tracheotomy. Bacterial identification and antibiotic susceptibility tests were performed on all specimens with a VITEK 2 system (bioMérieux, Marcy l'Etoile, France) in the Department of Microbiology in our hospital, ${ }^{4,5}$ and the following standard quality control strains were obtained from the National Committee for Clinical Laboratory Standards of China: Pseudomonas aeruginosa ATCC 27853, Staphylococcus aureus ATCC 25923, and Escherichia coli ATCC 25922.

The $\mu$ test, description of measurement, and enumeration of data were performed using SPSS 11.0 (SPSS Inc, Chicago, IL). The central tendency was described by arithmetic mean, and the relative number was demonstrated with the ratio and frequency. Statistical significance was defined as $P<0.05$.

\section{Results}

A total of 428 neurocritical patients were enrolled in this study: 225 were females and 203 were males. The demographics, underlying diseases, and outcomes of these patients are shown in Table 1. The median age was 61.2 years, and the median length of the hospital stay was 7.4 days. Thirty patients $(7 \%)$ died during the period of admission.

A total of 400 pathogenic strains were detected in 947 sputum specimens with a $42.2 \%$ positive rate. Of these strains, 276 were Gram-negative bacteria, accounting for $69.0 \%$ of total species, and included Klebsiella pneumonia, P. aeruginosa, and Acinetobacter baumannii. Among the strains collected, forty were Gram-positive bacteria, accounting for $10.0 \%$, and included S. aureus, Staphylococcus epidermidis, and
Table I The demographics, underlying diseases, and outcomes of inpatients

\begin{tabular}{ll}
\hline Variable & Values \\
\hline Median age & 61.2 years (16-89) \\
Gender & \\
Male & $225(52.6 \%)$ \\
Female & $203(47.4 \%)$ \\
Admission diagnosis & \\
Cerebral infarction & $140(32.7 \%)$ \\
Intracerebral hemorrhage & $69(16.1 \%)$ \\
Subarachnoid hemorrhage & $38(8.9 \%)$ \\
Encephalitis & $48(11.2 \%)$ \\
Tuberculous meningitis & $15(3.5 \%)$ \\
Multiple sclerosis & $27(6.3 \%)$ \\
Guillain-Barre syndrome & $20(4.7 \%)$ \\
Acute myelitis & $12(2.8 \%)$ \\
Status epilepticus & $35(8.2 \%)$ \\
Encephalopathy & $24(5.6 \%)$ \\
Median length of NICU stay & 7.4 days $(2-30)$ \\
Outcome & \\
Discharged & $398(93.0 \%)$ \\
Mortality & $30(7.0 \%)$ \\
\hline
\end{tabular}

Hemolytic staphylococcus. A total of 84 strains were fungi, including Candida albicans (Table 2).

Imipenem was the most effective antibiotic for the treatment of Gram-positive and Gram-negative bacteria. The drug resistance rate of Gram-positive bacteria was $100 \%$ to penicillin $\mathrm{G}$ and above $80 \%$ to erythromycin, azithromycin, and clarithromycin. Gram-positive bacteria were $100 \%$ sensitive to teicoplanin, vancomycin, and linezolid. The antibiotic

Table 2 The distribution and ratio of pulmonary infection pathogens in NICU

\begin{tabular}{lll}
\hline Bacterium & Numbers (strain) & Percentage \\
\hline Gram-negative bacteria & 276 & 69.0 \\
Klebsiella pneumoniae & 82 & 20.5 \\
Pseudomonas aeruginosa & 62 & 15.5 \\
Acinetobacter baumannii & 48 & 12.0 \\
Pseudomonas maltophilia & 14 & 3.5 \\
Enterobacter cloacae & 10 & 2.5 \\
Flu hemophilic bacteria & 6 & 1.5 \\
Acinetobacter junii & 4 & 1.0 \\
Enterobacter aerogenes & 4 & 1.0 \\
Others & 46 & 11.5 \\
Gram-positive bacteria & 40 & 10.0 \\
Staphylococcus aureus & 10 & 2.5 \\
Staphylococcus epidermidis & 10 & 2.5 \\
Hemolytic staphylococcus & 7 & 1.75 \\
Others & 13 & 3.25 \\
Fungus & 84 & 21.0 \\
Candida albicans & 49 & 12.25 \\
Candida tropicalis & 15 & 3.75 \\
Others & 20 & 5.0 \\
\hline
\end{tabular}


Table 3 Resistance rates of common Gram-negative bacilli to antibiotics (\%)

\begin{tabular}{|c|c|c|c|}
\hline Antibiotics & $\begin{array}{l}\text { Klebsiella } \\
\text { pneumoniae } \\
(\mathbf{N}=\mathbf{8 2})\end{array}$ & $\begin{array}{l}\text { Pseudomonas } \\
\text { aeruginosa } \\
(\mathbf{N}=62)\end{array}$ & $\begin{array}{l}\text { Acinetobacter } \\
\text { baumannii } \\
(\mathbf{N}=\mathbf{4 8})\end{array}$ \\
\hline Ampicillin & 100 & 100 & 100 \\
\hline Co-trimoxazole & 100 & 100 & 100 \\
\hline Amoxicillin & 100 & - & 100 \\
\hline Cephalothin & 100 & - & 100 \\
\hline Cefotaxime & 100 & - & 100 \\
\hline Netilmicin & 100 & - & 100 \\
\hline Cefuroxime & 100 & - & 100 \\
\hline Ticarcillin & 100 & 95.16 & 100 \\
\hline Piperacillin & 100 & 61.29 & 100 \\
\hline Cefazolin & 90 & 100 & 100 \\
\hline $\begin{array}{l}\text { Ampicillin/ } \\
\text { sulbactam }\end{array}$ & 90 & 100 & 87.50 \\
\hline Gentamicin & 82.72 & 75.38 & 72.92 \\
\hline Nitrofurantoin & 80 & 100 & 100 \\
\hline Ceftriaxone & 76.25 & 100 & 100 \\
\hline Cefepime & 72.84 & 55.38 & 55.32 \\
\hline $\begin{array}{l}\text { Trimethoprim/ } \\
\text { sulfamethoxazole }\end{array}$ & 72.5 & 100 & 86.96 \\
\hline Aztreonam & 72.5 & 67.21 & 78.26 \\
\hline Tetracycline & 72 & 100 & 100 \\
\hline Ceftazidime & 71.6 & 66.15 & 77.08 \\
\hline Ceftizoxime & 62 & 96.55 & 76.67 \\
\hline $\begin{array}{l}\text { Ticarcillin/ } \\
\text { clavulanic acid }\end{array}$ & 60.78 & 95.08 & 68.97 \\
\hline Tobramycin & 60.49 & 73.85 & 60.42 \\
\hline Amikacin & 56.25 & 37.70 & 34.78 \\
\hline Ciprofloxacin & 54.34 & 76.92 & 75 \\
\hline Levofloxacin & 51.25 & 59.02 & 17.02 \\
\hline $\begin{array}{l}\text { Piperacillin/ } \\
\text { tazobactam }\end{array}$ & 16.25 & 28.13 & 20 \\
\hline Cefotetan & 10 & 100 & 100 \\
\hline Ertapenem & 10 & - & - \\
\hline Imipenem & 1.23 & 35.38 & 2.08 \\
\hline Cefoxitin & 0 & - & 100 \\
\hline Meropenem & 0 & 43.10 & 0 \\
\hline
\end{tabular}

resistance rates of common Gram-negative bacilli and Gram-positive cocci are shown in Tables 3 and 4.

A total of 36 strains were detected from 30 deceased inpatients; 14 of these were fungal strains, with a $38.9 \%$ positive rate. A total of 364 strains were detected in 398 discharged inpatients, with 70 fungal strains with a $19.2 \%$ positive rate. When the positive rates of fungal infection in the mortality and discharged groups were compared, a statistical difference was found $(P<0.05)$.

\section{Discussion}

Patients in the NICU are always dangerously ill, and most of them display limited activity and consciousness disturbances.
Pulmonary infection is the most common complication for these patients. In this study, we investigated the distribution and antimicrobial susceptibility of pathogenic bacteria associated with pulmonary infection in inpatients in NICU. Pathogenic bacteria were defined when bacterial identification determined that the same pathogenic bacteria two successive or predominant bacteria growth was observed 3 times. Thus, only 400 strains of pathogens were detected with a $42.2 \%$ positive rate. Finally, we analyzed the positive strains and found that a low positive rate did not affect the level of bacteria distribution or the resistance rate.

In our NICU, the most common pathogens associated with pulmonary infection were Gram-negative bacilli, accounting for $69.0 \%$; this finding is in accordance with reports that Gram-negative bacteria are the most common pathogens associated with nosocomial infections. ${ }^{6}$ In the general population, the majority of pulmonary infections are caused by $S$. pneumoniae, but in our NICU, the three most common pathogens associated with pulmonary infection were $K$. pneumonia, $P$. aeruginosa, and $A$. baumannii. Our data show that $K$. pneumonia, $P$. aeruginosa, and $A$. baumannii have high resistance rates to penicillins, with the exception of piperacillin/ tazobactam. Studies have shown that drug-resistant mechanism for penicillins may be mainly due to the fact that the bacterium produces $\beta$-lactamase, which breaks open the $\beta$-lactam ring of the antibiotic, rendering the penicillins ineffective. ${ }^{7} \mathrm{~K}$. pneumonia and $A$. baumannii are relatively efficient to carbapenems, and resistance rates for imipenem are $1.23 \%$ and $2.08 \%$, respectively; both are efficient to meropenem. Carbapenem antibiotics gain access to the cytoplasm and combine with penicillin-binding protein (PBP) through the proteins with permeability on bacterial outer membrane, by interfering with cell wall synthesis and thus sterilize, because the majority of $\beta$-lactamase have with a high degree of stability, so the treatment can achieve a better efficacy. ${ }^{8}$ Clinicians can use carbapenem antibiotics as empiric antibiotics to treat infections caused by K. pneumonia and A. baumannii. ${ }^{9}$ After obtaining drug susceptibility data, we can rationally adjust the concentrations of effective antibiotics.

$P$. aeruginosa showed a resistance rate of more than $30 \%$ to imipenem and meropenem. This rate is higher than that reported in literature. ${ }^{6}$ Piperacillin/tazobactam as combination therapy against $P$. aeruginosa showed the lowest resistance rate. ${ }^{10}$ Prevalence of $P$. aeruginosa has gradually increased and has become one of the major pathogenic 
Table 4 Resistance rates of common Gram-positive cocci to antibiotics (\%)

\begin{tabular}{|c|c|c|c|}
\hline Antibiotics & $\begin{array}{l}\text { Staphylococcus aureus } \\
(N=10)\end{array}$ & $\begin{array}{l}\text { Staphylococcus epidermidis } \\
(N=10)\end{array}$ & $\begin{array}{l}\text { Hemolytic staphylococcus } \\
(\mathbf{N}=7)\end{array}$ \\
\hline Penicillin G & 100 & 100 & 100 \\
\hline Erythromycin & 100 & 80 & 100 \\
\hline Azithromycin & 100 & 80 & 100 \\
\hline Clarithromycin & 100 & 80 & 100 \\
\hline Ciprofloxacin & 100 & 70 & 100 \\
\hline Tetracycline & 100 & 20 & 14.29 \\
\hline Amoxicillin & 90 & 90 & 100 \\
\hline Ampicillin/sulbactam & 90 & 90 & 100 \\
\hline Cefaclor & 90 & 90 & 100 \\
\hline Oxacillin & 90 & 90 & 85.71 \\
\hline Gentamicin & 90 & 50 & 100 \\
\hline Imipenem & 88.89 & 90 & 100 \\
\hline Ceftriaxone & 88.89 & 90 & 100 \\
\hline Cefuroxime & 88.89 & 90 & 100 \\
\hline Cefotaxime & 88.89 & 90 & 100 \\
\hline Rifampicin & 70 & 40 & 14.29 \\
\hline Fosfomycin & 44.44 & 10 & 100 \\
\hline Trimethoprim/sulfamethoxazole & 42.86 & 90 & 60 \\
\hline Moxifloxacin & 33.33 & 10 & 0 \\
\hline Fusidate & 22.22 & 10 & 0 \\
\hline Dalfopristin & 0 & 0 & 0 \\
\hline Linezolid & 0 & 0 & 0 \\
\hline Teicoplanin & 0 & 0 & 0 \\
\hline Vancomycin & 0 & 0 & 0 \\
\hline
\end{tabular}

bacteria in the ICU. ${ }^{11,12}$ Some researchers have found that carbapenem-resistant $P$. aeruginosa is a risk factor for patient mortality. ${ }^{13}$ The resistance mechanisms include the production of $\beta$-lactamses, efflux pumps, and target-site or outer membrane modifications. ${ }^{14}$

Gram-positive bacteria were the least prevalent group of pathogens found in the NICU and include S. aureus, S. epidermidis, and Hemolytic staphylococcus. These strains are sensitive to teicoplanin and vancomycin, show high sensitivity to rifampicin, and are resistant to penicillin antibiotics. These findings are in accordance with the literature. ${ }^{15,16}$

In our study, we found that fungus was the second largest group of pathogens associated with pulmonary infection in our NICU. This proportion (21\%) is higher than that reported in literature. ${ }^{17} \mathrm{C}$. albicans is the most common fungal pathogen and is effective to fluconazole. One study showed that invasive fungal infections have become a major cause of morbidity and mortality in ICU, and invasive candidiasis accounts for up to $15 \%-30 \%$ of all nosocomial infections in critically ill patients. ${ }^{18}$ We also found that fungal infection seemed to be related to mortality in our NICU. There are some reasons to explain the high proportions of fungal infections in the NICU. First, using broad-spectrum antibiotics might inhibit the normal flora in the body and cause malignant growth of fungi. Second, patients in the NICU are severely ill with low immunity and high vulnerability to fungal infection. Finally, some medications commonly used to treat nervous system diseases, such as glucocorticoids, could cause disorder to the balance of the microecology in the body, causing dysbacteriosis and inducing increased fungal infection.

Currently, antibacterial resistance has become a serious problem in the NICU. This study was carried out at a single center, and our goal was to understand the changes in the distribution of bacterial strains and bacterial resistance in the NICU. We found that Gram-negative bacteria are still the most common pathogens associated with nosocomial pulmonary infections, whereas the percentages of fungal infection are higher than those reported in the literature and more related to mortality in our NICU. Bacteria are highly resistant to commonly used antibiotics, so bacterial culture and drug susceptibility tests are necessary for rationalizing the use of antibiotics and for correctly taking standard preventive measures and care.

\section{Disclosure}

The authors have no conflict of interest to declare. 


\section{References}

1. Musa SA, Robertshaw H, Thomson SJ, Cowan ML, Rahman TM. Clostridium difficile-associated disease acquired in the neurocritical care unit. Neurocrit Care. 2010;13(1):87-92.

2. Agbaht K, Diaz E, Muñoz E, et al. Bacteremia in patients with ventilator-associated pneumonia is associated with increased mortality: a study comparing bacteremic vs nonbacteremic ventilator-associated pneumonia. Crit Care Med. 2007;35(9):2064-2070.

3. L'Hériteau F, Alberti C, Cohen Y, Troché G, Moine P, Timsit JF. Nosocomial infection and multidrug-resistant bacteria surveillance in intensive care units: a survey in France. Infect Control Hosp Epidemiol. 2005;26(1):13-20.

4. Delmas J, Chacornac JP, Robin F, Giammarinaro P, Talon R, Bonnet R. Evaluation of the Vitek 2 system with a variety of Staphylococcus species. J Clin Microbiol. 2008;46(1):311-313.

5. Nakasone I, Kinjo T, Yamane N, Kisanuki K, Shiohira CM. Laboratory-based evaluation of the colorimetric VITEK-2 Compact system for species identification and of the Advanced Expert System for detection of antimicrobial resistances: VITEK-2 Compact system identification and antimicrobial susceptibility testing. Diagn Microbiol Infect Dis. 2007;58(2):191-198.

6. Shi MY, Xie HF, Wei JP. Investigation of pathogenic bacteria for pulmonary infections and their drug resistance in neurological intensive care unit. Di Yi Jun Yi Da Xue Xue Bao. 2004;24(12):1441-1443.

7. Mesaros N, Nordmann P, Plésiat $P$, et al. Pseudomonas aeruginosa: resistance and therapeutic options at the turn of the new millennium. Clin Microbiol Infect. 2007;13(6):560-578.

8. Fernández-Cuenca F, Martínez-Martínez L, Conejo MC, Ayala JA, Perea EJ, Pascual A. Relationship between beta-lactamase production, outer membrane protein and penicillin-binding protein profiles on the activity of carbapenems against clinical isolates of Acinetobacter baumannii. J Antimicrob Chemother. 2003;51(3):565-574.
9. Karageorgopoulos DE, Falagas ME. Current control and treatment of multidrug-resistant Acinetobacter baumannii infections. Lancet Infect Dis. 2008;8(12):751-762.

10. Lodise TP Jr, Lomaestro B, Drusano GL. Piperacillin-tazobactam for Pseudomonas aeruginosa infection: clinical implications of an extendedinfusion dosing strategy. Clin Infect Dis. 2007;44(3):357-363.

11. Gladstone $P$, Rajendran P, Brahmadathan KN. Incidence of carbapenem resistant nonfermenting gram negative bacilli from patients with respiratory infections in the intensive care units. Indian J Med Microbiol. 2005;23(3):189-191.

12. Obritsch MD, Fish DN, MacLaren R, Jung R. Nosocomial infections due to multidrug-resistant Pseudomonas aeruginosa: epidemiology and treatment options. Pharmacotherapy. 2005;25(10):1353-1364.

13. Vitkauskienė A, Skrodenienè E, Dambrauskienė A, Macas A, Sakalauskas R. Pseudomonas aeruginosa bacteremia: resistance to antibiotics, risk factors, and patient mortality. Medicina (Kaunas). 2010;46(7):490-495.

14. Zavascki AP, Carvalhaes CG, Picão RC, Gales AC. Multidrug-resistant Pseudomonas aeruginosa and Acinetobacter baumannii: resistance mechanisms and implications for therapy. Expert Rev Anti Infect Ther. 2010;8(1):71-93.

15. Deresinski S. Vancomycin in combination with other antibiotics for the treatment of serious methicillin-resistant Staphylococcus aureus infections. Clin Infect Dis. 2009;49(7):1072-1079.

16. Falagas ME, Bliziotis IA, Fragoulis KN. Oral rifampin for eradication of Staphylococcus aureus carriage from healthy and sick populations: a systematic review of the evidence from comparative trials. Am J Infect Control. 2007;35(2):106-114.

17. Gullo A. Invasive fungal infections: the challenge continues. Drugs. 2009;69 Suppl 1:65-73.

18. Vazquez JA. Invasive fungal infections in the intensive care unit. Semin Respir Crit Care Med. 2010;31(1):79-86.
Therapeutics and Clinical Risk Management

\section{Publish your work in this journal}

Therapeutics and Clinical Risk Management is an international, peerreviewed journal of clinical therapeutics and risk management, focusing on concise rapid reporting of clinical studies in all therapeutic areas, outcomes, safety, and programs for the effective, safe, and sustained use of medicines. This journal is indexed on PubMed Central, CAS,

\section{Dovepress}

EMBase, Scopus and the Elsevier Bibliographic databases. The manuscript management system is completely online and includes a very quick and fair peer-review system, which is all easy to use. Visit http://www.dovepress.com/testimonials.php to read real quotes from published authors. 